\title{
Antithymocyte globulin-induced atypical haemorrhagic posterior reversible encephalopathy syndrome in severe aplastic anaemia
}

\author{
Tribikram Panda (D) ,' Mukul Aggarwal (D) ,' ${ }^{1}$ Priyanka Naranje, ${ }^{2}$ \\ Manoranjan Mahapatra ${ }^{1}$
}

'Hematology, All India Institute of Medical Sciences, New Delhi, India

${ }^{2}$ Radiodiagnosis, All India Institute of Medical Sciences, New Delhi, India

\section{Correspondence to Dr Mukul Aggarwal;} mukulmamc@gmail.com

Accepted 24 June 2021

\section{DESCRIPTION}

Posterior reversible encephalopathy syndrome (PRES) is characterised by headache, altered mental status, seizures and visual loss that resolve spontaneously in a short span of time. The typical radiographic findings include symmetrical hyper intensities in Magnetic Resonance Fluid Attenuated Inversion Recovery (MR FLAIR) images in posterior parieto-occipital lobes. ${ }^{1}$ Severe aplastic anaemia (SAA) is a potentially fatal bone marrow failure disorder, treated by allogenic stem cell transplantation or antithymocyte globulin (ATG) with or without eltrombopag. Here, we report images of atypical PRES with uncommon radiological findings complicated with superimposed haemorrhage in a patient with SAA receiving ATG, described as haemorrhagic PRES.

A young man presented with fatigue, symptomatic anaemia, intermittent fever and skin and gum bleeding since last 1.5 years. He was diagnosed with SAA. His FLAER for paroxysmal nocturnal haemoglobinuria and chromosomal breakage analysis for fanconi anaemia were normal. He was treated with ATG $(40 \mathrm{mg} / \mathrm{kg} /$ day for 4 days) with concomitant prednisolone $(1 \mathrm{mg} / \mathrm{kg} /$ day $)$ and regular packed red blood cells (RBC) and apheresis platelet support. Cyclosporine was stopped a week prior to ATG. On day 6 of therapy, he had an episode of generalised tonic clonic seizure, and on day 7 , he had status epilepticus. There were no focal deficits or visual disturbances. His blood pressure and serum electrolytes were normal. His initial CT scan of brain (on day 6) was normal. Repeated CT (day 7) showed symmetrical hypodense areas in bilateral

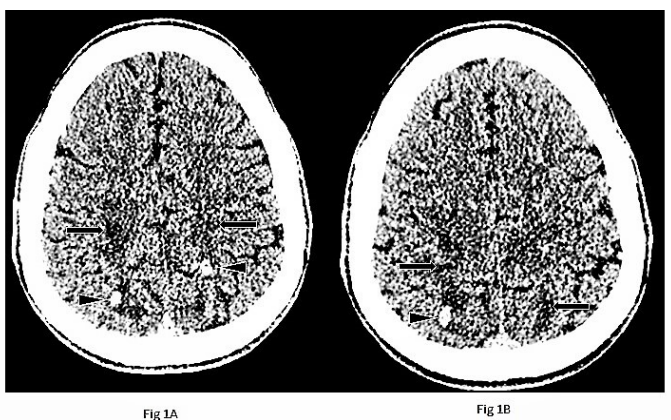

Figure 1 (A) and (B) Non-contrast CT head shows hypodense areas in bilateral parieto-occipital white matter (arrows) with hyper dense foci of haemorrhages (arrowheads).
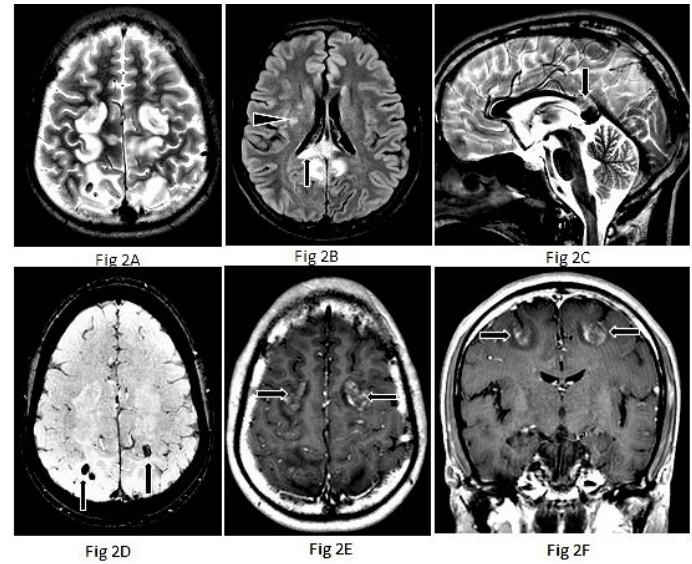

Figure 2 Brain MRI in atypical PRES showing T2 weighted image (T2WI) symmetrical hyper-intensities in sub cortical white matter of bilateral fronto-parietal regions (A). Hyper-intense areas in splenium of corpus callosum (arrow) and right basal ganglia (arrowhead) are also noted (B, and C). Susceptibility Weighted Imaging (SWI) shows focal areas of blooming in bilateral parietal regions consistent with haemorrhage (arrows) (D). Arrows show postcontrast images with heterogeneous enhancement in affected regions ( $E$ and F). PRES, posterior reversible encephalopathy syndrome.

parieto-occipital white matter with areas of haemorrhages figure 1A, B. MRI showed symmetrical T2/FLAIR hyperintensity in subcortical white matter predominantly in bilateral posterior frontoparietal and occipital regions. Similar signal changes were also noted in the splenium of corpus callosum and right basal ganglia. These regions demonstrated heterogeneous enhancement on postcontrast images. In addition, there were foci of superimposed haemorrhages in bilateral parietal white matter figure $2 \mathrm{~A}-\mathrm{F}$. None of the lesions showed diffusion restriction. Overall, features were suggestive of atypical haemorrhagic PRES. He improved, remained seizure free with phenytoin, levetiracetam and other supportive care. In view of his rapid clinical improvement with above radiological findings and supportive measures, angiogram was not done in our case. Subsequently, cyclosporine was started from day 15 of ATG and phenytoin discontinued. The patient is currently 9 months follow-up post-ATG and is doing well on cyclosporine, without any neurological sequelae. 
Very few cases of PRES in SAA following ATG only have been described until, commonly complicated by hypertension with typical posterior parieto-occipital involvement. ${ }^{2} 3$ Our patient was normotensive with atypical areas of involvement complicated by haemorrhage. Hypertensive encephalopathy, endothelial dysfunction and altered cerebral vascular dynamics are the proposed mechanisms for PRES. A typical distribution (frontal, cerebellar, basal ganglia, brain stem, splenium of corpus callosum, deep white matter), asymmetric or unilateral involvement can be seen as a spectrum of atypical PRES. ${ }^{4}$ Around 15\% of PRES can be complicated by haemorrhage of varying patterns (large, focal/multiple minute foci/subarachnoid) possibly due to vasculopathy and associated hypertension. But the degree of hypertension does not correlate with the severity, pattern of haemorrhage in PRES. ${ }^{5}$ PRES and reversible cerebral vasoconstriction syndrome (RCVS) share similar clinical and radiological

\section{Learning points}

Antithymocyte globulin (ATG) alone can lead to manifestations of posterior reversible encephalopathy syndrome, with or without haemorrhage.

- Acute hypertension, corticosteroids and cyclosporine use are common confounders in such settings.

- In a patient undergoing ATG-based therapy who develops acute onset neurological symptoms, high index of suspicion, urgent imaging and prompt initiation of therapy are imperative to better outcomes. features. Prognosis and outcome can vary from self-limiting to death from stroke and complications. ${ }^{6}$ It is difficult to differentiate both clinically. RCVS should be considered as a differential diagnosis in appropriate clinical context.

Contributors TP and MA conceptualised the idea, prepared the manuscript. MA, MM, PN edited and critically analysed the manuscript.

Funding The authors have not declared a specific grant for this research from any funding agency in the public, commercial or not-for-profit sectors.

Competing interests None declared.

Patient consent for publication Obtained.

Provenance and peer review Not commissioned; externally peer reviewed.

\section{ORCID iDs}

Tribikram Panda http://orcid.org/0000-0001-9009-1302

Mukul Aggarwal http://orcid.org/0000-0002-9885-1625

\section{REFERENCES}

1 Bartynski WS. Posterior reversible encephalopathy syndrome, part 1: fundamental imaging and clinical features. AJNR Am J Neuroradiol 2008;29:1036-42.

2 Greaves P, Oakervee H, Kon SSC, et al. Posterior reversible encephalopathy syndrome following anti-lymphocyte globulin treatment for severe aplastic anaemia. $\mathrm{Br}$ J Haematol 2006;134:251.

3 Dayama A, Seth T, Mishra P, et al. Antithymocyte globulin induced posterior reversible encephalopathy in aplastic anemia. Neurol India 2013;61:430-1.

4 Stevens CJ, Heran MKS. The many faces of posterior reversible encephalopathy syndrome. Br J Radiol 2012;85:1566-75.

5 Hefzy HM, Bartynski WS, Boardman JF, et al. Hemorrhage in posterior reversible encephalopathy syndrome: imaging and clinical features. AJNR Am J Neuroradiol 2009;30:1371-9.

6 Pilato F, Distefano M, Calandrelli R. Posterior reversible encephalopathy syndrome and reversible cerebral vasoconstriction syndrome: clinical and radiological considerations. Front Neurol 2020;11:34.

Copyright 2021 BMJ Publishing Group. All rights reserved. For permission to reuse any of this content visit

https://www.bmj.com/company/products-services/rights-and-licensing/permissions/

BMJ Case Report Fellows may re-use this article for personal use and teaching without any further permission.

Become a Fellow of BMJ Case Reports today and you can:

- Submit as many cases as you like

- Enjoy fast sympathetic peer review and rapid publication of accepted articles

- Access all the published articles

Re-use any of the published material for personal use and teaching without further permission

Customer Service

If you have any further queries about your subscription, please contact our customer services team on +44 (0) 2071111105 or via email at support@bmj.com.

Visit casereports.bmj.com for more articles like this and to become a Fellow 